\title{
Examining the Effect of Motivation on Short-term Memory Recalling of Arabic Abstract and Concrete Words Using Free, Cued, and Serial Recall Paradigms
}

\author{
Yasir Saad Almukhaizeem ${ }^{1}$, Ahmed Mohammed Saleh Alduais ${ }^{2}$
}

\section{ABSTRACT}

Purpose: : The present paper explores whether a correlation exists between motivation and short-term memory recalling and examines motivation as a factor affecting memory recalling of Arabic concrete and abstract words through free, cued, and serial recall tasks.

Method: Four groups of undergraduates at King Saud University, Saudi Arabia participated in this study. The first group consisted of 9 undergraduates who were trained to perform three types of recall for 20 Arabic abstract and concrete words. The second, third and fourth groups consisted of 27 undergraduates where each group member was trained only to perform one recall type: free recall, cued recall and serial recall respectively. Motivation was the independent variable and number of recalled abstract and concrete words was the dependent variable. The used materials in this study were: abstract and concrete words classification form based on four factors distributed to the participants (concreteness, image ability, meaningfulness, and age of acquisition), three oral recall forms, three written recall forms, and observation sheets for each type of recall. Three methods were used: auditory, visual, and written.

Results: The statistical analysis indicated that the percentage of the retrieved words by the control group was slightly lower than that of the experimental group in the case of free and serial recall paradigms. In other words, the effect of motivation on short-term memory recall was found partial. A Pearson product-moment correlation coefficient was also computed to assess the relationship between motivation (one recall trail, that is recalling only either freely, supportably (with cues), or serially [as compared to those who recalled the words freely, supportably, and serially) and short-term memory recall (recalled Arabic abstract and concrete words). The participants with a motivational stimulus tended to recall slightly more Arabic abstract and concrete words, whereas those participants with no motivational stimulus tended to recall slightly less Arabic abstract and concrete words, $\mathrm{r}=.713$, $\mathrm{p}<0.01$.

Conclusions: Motivation effect on short-term memory recall of Arabic abstract and concrete words was not significant especially in the case of free and serial recall paradigms. However, Pearson's correlation supported the research hypothesis that there was a moderate positive correlation between the two variables, $r=0.713, \mathrm{n}=440, \mathrm{p}=0.000$, with $\mathrm{R}^{2}=.508$.

Keywords: Abstract Words; Concrete Words; Words Processing; Words Recall; Free Recall;

\section{Cued Recall; Serial Recall; Recall Effects}

\footnotetext{
${ }^{1}$ Department of Linguistics and Translation, College of Languages and Translation, King Saud University, Riyadh, Kingdom of Saudi Arabia

${ }^{2}$ Department of Linguistics, Social Sciences Institute, Ankara University, Sihhiye, Ankara, Turkey

(C) 2015 I A Yasir, A Alduais; licensee IJIP. This is an Open Access Research distributed under the terms of the Creative Commons Attribution License (http://creativecommons.org/licenses/by/2.0), which permits unrestricted use, distribution, and reproduction in any Medium, provided the original work is properly cited.
} 


\section{Examining the Effect of Motivation on Short-term Memory Recalling of Arabic Abstract and Concrete Words Using Free, Cued, and Serial Recall Paradigms}

Principal factors affecting memory recall (see Menzel, 2008; Baddeley, 1999; Baddeley, 2004; Parker, Wilding \& Bussey, 2002); Noordman-Vonk, 1979; Eichenbaum, 2002; Byrne, 2003) are illustrated in the figure (1) below.

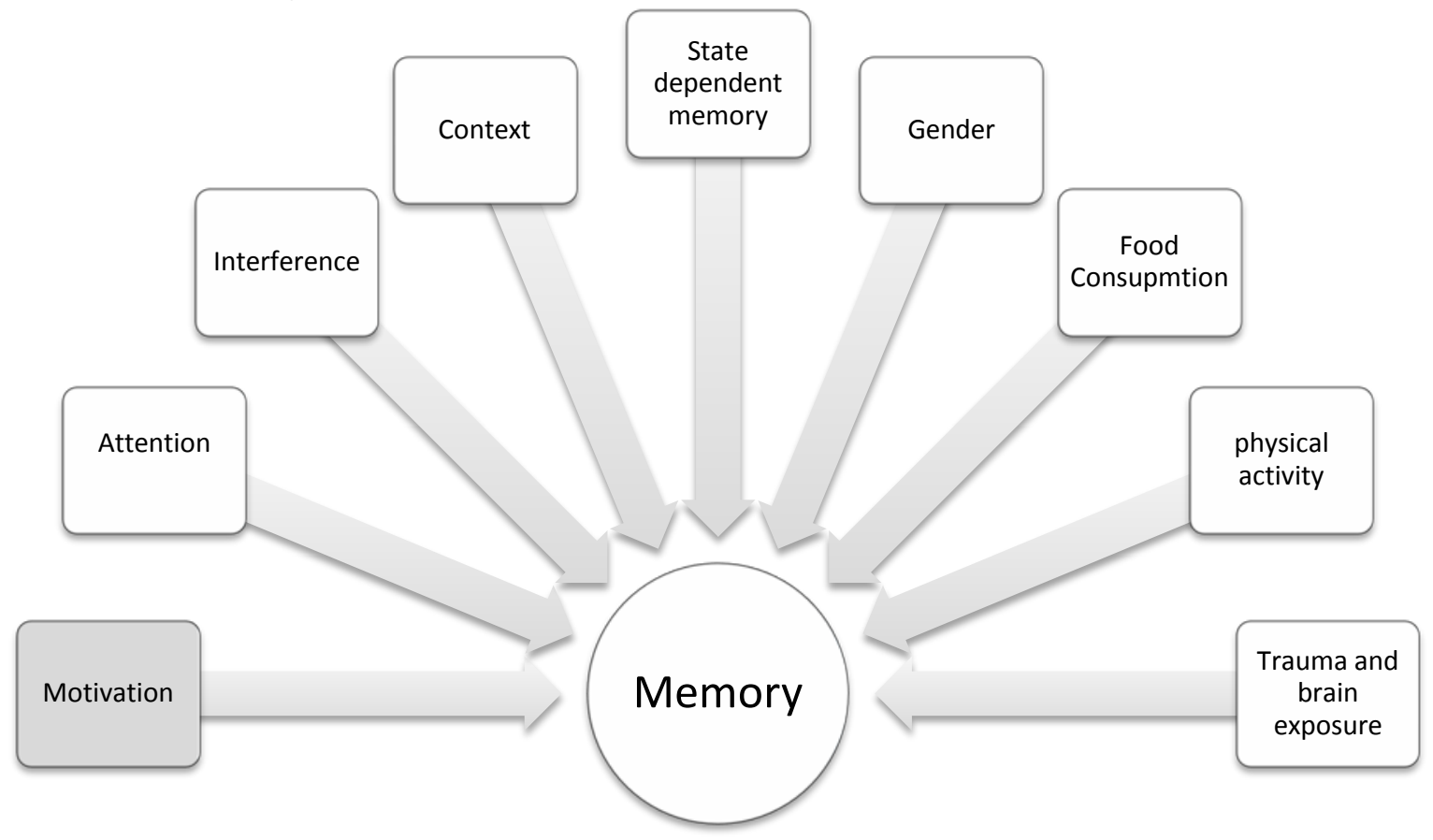

[Figure 1: Factors affecting memory recall]

The factor which will be examined in this paper is motivation. Motivation is defined as 'the sum of separate motives that arouse, sustain and regulate certain behavior in an individual', (Fuchs, 2014, para 2). It is also defined as 'the driving force behind the energy required completing a task.' A lack of motivation will give rise to a lack of driving power behind completing a certain task.(Psychology Dictionary, 2012, para 2). It is the 'mental processes that arouse, sustain, and direct human behaviour. Motivation may stem from processes taking place within an individual (intrinsic motivation) or from the impact of factors acting on the individual from outside (extrinsic motivation), (Oxford Index, 2014, para 1). Further, motivation has a number of types as illustrated in figure 3 (see Benjamin \& Ross, 2007; Bower, 1969; Bower, 1991). Other classifications of motivation -like integrative or instrumental are possible too. See Oller (as cited in Baker, 1996) and Oller \& Eilers 2002), and also Conway, (1997); Cowan, (2005); Faust, (2012); Foster, (2009); Greene, (1987); Kliegel, McDaniel, \&Einstein, (2008); Mace, (2007); Mense, Debney, \& Druce, (2006); Pickering, (2006) and Randall, (2007), for more details about memory. 


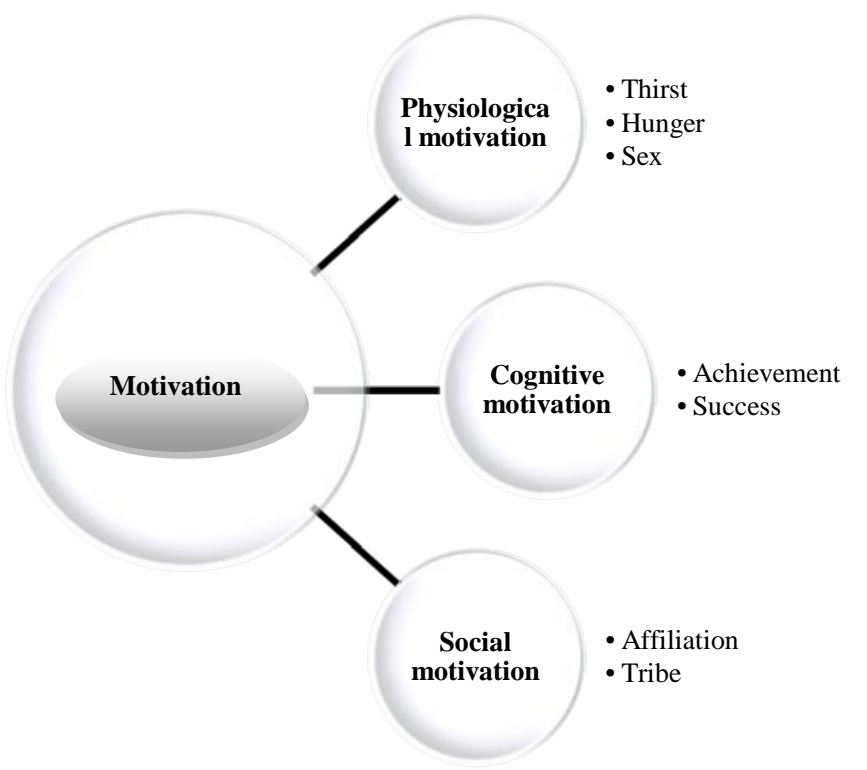

[Figure 2: General Types of Motivation]

Many studies were conducted examining the effect of motivation on word recall. For instance, a minor motivation effect on episodic memory performance in terms of word recall [retrieval] and word recognition [encoding] by (Ngaosuvan, 2004). Furthermore, it has been widely observed that only in intensive and various other kinds of motivation there has been an effect on episodic memory performance during word recall and recognition. (Ngaosuvan, 2004; Ngaosuvan \& Mantyla, 2005). Oller and Perkins (as cited in Baker, 1996 \& and UK Essays, 2014a) declare that motivation, be it positive or negative affects language learning and/or acquisition in general.

In spite of this, other studies approved minor and/or zero effect of motivation on memory recall. An experimental study investigated the effect of motivation on memory recall mainly, free words recall. In this study, it was concluded that there was an insignificant difference between the control group and the experimental group in the number of recalled words from the list of 20 words which were provided to the two groups, (UKEssays, 2014b).

It is well-known that long-term memory over short-term memory in recalling and storing abilities albeit the different between two types of memory incomparable (UKEssays, 2014c). Many models have been proposed explaining human memory capacity. Among these models is the one proposed by (Atkinson \& Shiffrin, 1968), (Aitchison, 1987) as illustrated below. 


\section{Examining the Effect of Motivation on Short-term Memory Recalling of Arabic Abstract and Concrete Words Using Free, Cued, and Serial Recall Paradigms}

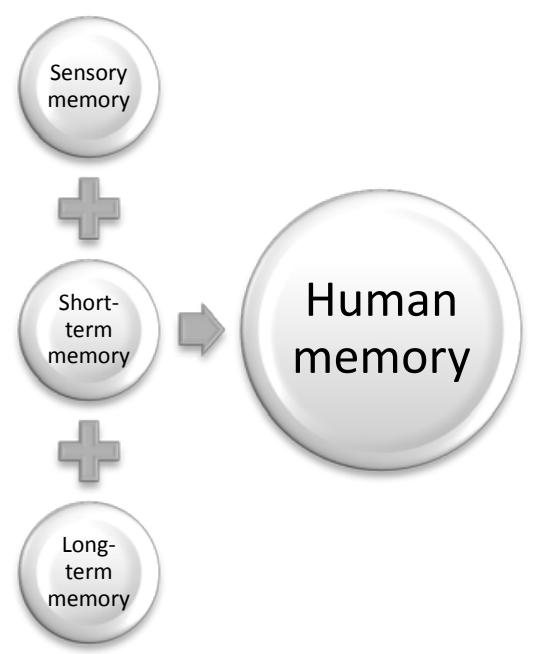

[Figure 3: Atkinson \& Shiffrin Human memory sequence stages]

A large number of studies have been conducted approving the positive effect of motivation on language learning and/or acquisition be it L1 or L2, that is first and and second language acquisition(s). For instance, Gardner's study (as cited in UKEssays, 2014e) stated that there is an intricate relationship between positive motivation and success in second language learning (see also Ellis, 1992; Ellis, 1997, Ellis, 2005, Ellis, Loewen, Elder, Erlam, Philp \& Reinders, 2009; Ellis, 2012).

Proposed theories which supported the view that motivation increases learning chances include: Attribution Theory, Self-determination Theory, Gardner's Socio-educational Model, Williams and Burden’s Socio-educational Constructivist Model, (UKEssays, 2014f).

Having introduced a number of the studies in relation to motivation, memory recall and language learning and/or acquisition, now it is worth to mention some studies in relation to recall of abstract and concrete words.

West \& Holcomb (2000) conducted an experimental study supporting the previously finding that concrete concepts and/or words over abstract ones in terms of cognitive processing. The study consisted of 36 students in the aged (19-23) and divided into three groups where each group represents one investigated level: imagery, semantic and surface levels. The researcher made use of Reaction Time (RE) and Even-Related brain Potential (ERP) as tool measurements for their research. The ERs were shorter in both the imagery and semantic tasks for concrete words than abstract ones specially the imagery task. Besides, concrete words elicited more negative ERPs than abstract ones.

Fliessbach, Weis, Klaver, Elger, \& Weber, (2006) examined abstract and concrete words processing on the basis of the notion that concrete words are generally better than abstract ones in terms of more successful remembering. The study was based on two theories, both supporting 


\section{Examining the Effect of Motivation on Short-term Memory Recalling of Arabic Abstract and Concrete Words Using Free, Cued, and Serial Recall Paradigms}

the view that concrete words, but not abstract ones are more accurately remembered. The first theory is called Dual-coding Theory and the second one is called Context-availability Theory. The former theory states that concrete words are over abstract ones because they possess "dual coding ... in the form of a verbal and sensory code”, (p. 1413). The latter theory states, again, that concrete words are over abstract ones because they possess "a more accessible semantic network”, (Fliessbach, Weis, Klaver, Elger, \& Weber, 2006, p. 1413). The researcher made use of the even-related Functional Magnetic Resonance Imaging (fMRI) technique as a tool for testing their proposed prediction. Twenty one (21) subjects without any neurological or psychiatric history in the age range (19-43) participated in the study. The material of the study was 180 abstract words and 180 concrete words, selected and identified as among the most frequent German words. The drawn conclusion was in favour of more significance in the case of concrete words over the abstract ones in terms of activated places in the brain.

Additionally, (Mestres-Misse', Mu“nte, \& Rodriguez-Fornells, 2008) examined the contextual acquisition of abstract and concrete words using a functional neuroanatomy approach. Fifteen native Spanish speakers with no neurological or psychiatric history participated in the study where 80 abstract words and 80 concrete words structured in paired sentences were used as material of the study. The tool of the study was fMRI. Results indicated different qualitative associations for the learned abstract and concrete words.

Walker \& Hulme, (1999) evaluated Immediate Serial Recall (ISR) and maximal speech rate (MSR) of abstract and concrete words differing in lengthin their study. Four experiments having been conducted, it was concluded was that concrete words had an advantage over abstract ones in as long as they could be recalled faster than the abstract ones.

Dukes\&Bastian, (1966) tested Immediate Free Recall (IFR) of abstract and concrete words using a list of 10 abstract words and 10 concrete words, more specifically nouns. The words were shown to the participants by a projector twice. They concluded that the participants recalled more concrete words than abstract ones.

Prior, Cumming \& Hendy, (1984), using dichotic listening paradigm hypothesis, tested and concluded that while concrete words were processed equally in both the left and right hemispheres of the brain, abstract words, on the contrary, had an advantage. The left hemisphere is superior in case of processing them. 16 female and 16 male subjects participated in the study using 110 paired items as a listening material. Results indicated no significant evidence showing differences in the role of both hemispheres of the brain in regard to abstract and concrete words.

Another perspective of searching on processing of abstract and concrete words is in the case of second language acquisition and/or more technically called psycholinguistic words information, or word learn ability. For example, (Salsbury, Crossley \& McNamara, 2011) conducted a 


\section{Examining the Effect of Motivation on Short-term Memory Recalling of Arabic Abstract and Concrete Words Using Free, Cued, and Serial Recall Paradigms}

longitudinal-study investigating this issue in terms of: concreteness, image ability, meaningfulness, and familiarity. The researchers made use of words from Medical Research Council (MRC) Psycholinguistic Database to analyse the collected words. Six L2 learners: (3 with Arabic Language as L1, 1 with Japanese Language as L1, 1 with Korean Language as L1, and 1 with Spanish Language as L1) who were attending an intensive English Language courses participated in this study and attended 18 sessions for a year. It was generally concluded that L2 learners of English Language show more positivity towards the learning of concrete words which is consistent with results of processing abstract and concrete words by L1 learners. In other words, abstract words are more difficult to remember and use even for L2 learners.

On the basis of this, this paper aims at studying the effect of motivation on memory recall of Arabic abstract and concrete words using free, cued, and serial recall paradigms. Put differently, it attempts answering the following questions:

1. Does motivation affect short memory recall?

a. Do the participants in the motivated group recall more words than do their counterparts who are not motivated?

2. Is there a correlation between motivation and memory recall of Arabic abstract and concrete words?

\section{METHOD}

\section{Sample}

The population of interest in this study is all university students in the undergraduate level who meet the following criteria:

1) are native-speakers of Arabic Language;

2) are registered in the university as undergraduate students; and,

3) have a normal neurological and clinical history. The following table (2) shows the characteristics of the subjects in this study.

\section{Table 1: characteristics of subjects}

\begin{tabular}{|l|l|}
\hline Age range & $20-24$ \\
\hline Mother tongue language & Arabic Language \\
\hline Dialect & Saudi Arabic Language \\
\hline Ethnicity & Arab \\
\hline Other languages & English (EFL use) \\
\hline Gender & Male (both single and married) \\
\hline Nationality & Saudis \\
\hline Specific characteristic & $\begin{array}{l}\text { Enrolled in a BA programme at the } \\
\text { university level (King Saud University). }\end{array}$ \\
\hline
\end{tabular}




\section{Examining the Effect of Motivation on Short-term Memory Recalling of Arabic Abstract and Concrete Words Using Free, Cued, and Serial Recall Paradigms}

Probability sampling method, mainly stratified sampling method was used in this study where one class out of many available classes was picked randomly to take part in this study. The class had 36 students from the college of Engineering who were enrolled for the prerequisite English Language course in the College of Languages and Translation, King Saud University, Riyadh, Kingdom of Saudi Arabia, in the late December, 2013. The class was divided randomly into two four groups as shown in table (2) below.

\section{Table (2): Population distribution}

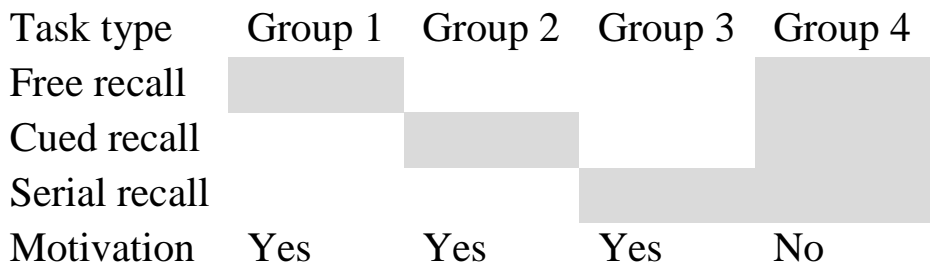

The selected sample is aimed to be representative of the population of interest and that reached results are generalizable for populations with similar characteristics. In other words, the study investigates a language acquisition topic from both the cognitive and psycholinguistic perspectives and the targeted population is native speakers of Arabic so external effects like time, place and people cannot affect the generalizability of this study as long as they have similar characteristics to the above mentioned ones.

\section{MEASURES}

Two measures were used in this study: one was a list of 20 Arabic abstract and concrete words and an observation sheet of the observed effects of recall types.

To start with the first measure, a list of 20 Arabic words where 20 are abstract and 20 are concrete was used in this study. The words were selected on the basis of semantic relationship where one word could relate to another in terms of meaning but differ from one another in terms of concreteness. For instance, the words: mind and brain which are both semantically related but actually different from one another. It should be noted that by stating semantically similar is to mean that they share same associations and a person can think of both words when provided by certain cues and/or associations.

The list of the 20 abstract and concrete words were selected to measure abstract and concrete words processing and recall through free call tasks. The list of the words, as well as the procedural issues could be followed in the procedures section below and in the appendix.

Both validity and reliability were calculated by measurement toolin this study. In detail, in the case of construct validity: both face and content validities were calculated to represent translation validity. Face validity was calculated by the principal researcher and another $\mathrm{PhD}$ student of 
Arabic Language from the Department of Arabic Language and Literature, College of Arts, King Saud University, Riyadh, Kingdom of Saudi Arabia. Both of them indicated very good face validity for the list of the words. For content validity, again, the list of the words was divided into two types in terms of content: abstract and concrete, yet in terms of semantic relationship between the abstract and concrete pair of words. In other words, the abstract word must have an association with the concrete words in order to be included in the list; otherwise, it will be excluded and replaced by another pair of words. One type only of criterion-related validity, namely, predictive validity, was calculated in this study (see tables $3 \& 5$ below).

To move to reliability, two types of reliability were calculated: inter-rater and internal consistency reliability. Inter-rater reliability was measured by the principal researcher who divided the words into two lists: abstract and concrete words on the basis of the following criteria: concreteness, image ability, meaningfulness (Paivio Norms), and age of acquisition, (MRC Psycholinguistic Database, 2013). The list of words was rated twice to make sure that the lists of the abstract words were those with negative significant concreteness, zero or negative image ability, and vague and/or ambiguous meaning(s), and the concrete words were those with positive significant concreteness, high or positive image ability, and clear-cut meaning(s). Tables (3-5) below display and summarize the calculated validity and reliability types and their values.

Table 3: Reliability \& validity results of abstract and concrete words scale

\begin{tabular}{|c|c|c|c|c|c|}
\hline \multirow[t]{2}{*}{ Reliability } & \multicolumn{2}{|c|}{ Statistical tool \& result } & \multirow[t]{2}{*}{ Validity } & \multicolumn{2}{|c|}{ Statistical tool \& result } \\
\hline & Tool & Result & & Tool & Result \\
\hline Inter-rater & Pearson & $.80, .80, .78$ & Face & 2 raters & High \\
\hline \multirow[t]{6}{*}{ Internal } & Cronbach & .82 & Content & Categories & Excellen \\
\hline & & & & & $\mathrm{t}$ \\
\hline & & & Predictive & Pearson & .49 \\
\hline & & & Concurrent & Uncalculated & \\
\hline & & & Convergent & Uncalculated & \\
\hline & & & Discriminate & Uncalculated & \\
\hline
\end{tabular}

Table 4: Internal consistency reliability of the abstract and concrete words scale

$\begin{array}{llll}\text { Feature } & \begin{array}{l}\text { Corrected } \\ \text { Cronbach's alpha }\end{array} & \begin{array}{l}\text { Cronbach's alpha if } \\ \text { item deleted }\end{array} \\ \text { Concreteness } & .71 & .78 \\ \text { Image ability } & .70 & .78 \\ \text { Meaningfulness } & .69 & .80 \\ \text { Concreteness and abstractness } & 1.00 & .71\end{array}$


Table 5: Construct validity of the abstract and concrete words scale Feature

\begin{tabular}{lllll} 
& R value & R Value & R value & R value \\
\hline Concreteness & .46 & .47 & .40 & .80 \\
Image ability & .46 & .44 & .37 & .80 \\
Meaningfulness & .46 & .44 & .38 & .78 \\
Age of acquisition & .40 & .37 & .38 & .49 \\
Concreteness and abstractness & .80 & .80 & .78 & .49
\end{tabular}

The second measure was an observation sheet wherein the administrator of the research was provided with to document his observations following the given instructions in the provided sheet (see appendix)

\section{DESIGN}

A four group quasi-experimental randomized design was used in this study. The design can be depicted in notational form as:

$\begin{array}{llll}\mathrm{R} & \mathrm{X}_{1,2,3}^{-} & \mathrm{O}_{1} & \mathrm{O}^{+}{ }_{1,2} \\ \mathrm{R} & \mathrm{X}_{1,2,3}^{-} & \mathrm{O}_{2} & \mathrm{O}^{+}{ }_{1,2} \\ \mathrm{R} & \mathrm{X}_{1,2,3}^{-} & \mathrm{O}_{3} & \mathrm{O}^{+}{ }_{1,2} \\ \mathrm{R} & \mathrm{X}_{1,2,3}^{-} & \mathrm{O}_{4} & \mathrm{O}^{-}{ }_{1,2}\end{array}$

where:

$\mathrm{R}=$ indicates that the groups were randomly assigned

$\mathrm{X}$ - = indicates words processing methods $(1=$ auditory, $2=$ visual, and $3=$ writing $),(-)$ indicates that it is non=treatment research

$\mathrm{O}=$ indicates the measurement tools used in the study

$\mathrm{O}=$ the first $\mathrm{O}$ stands for the observation sheet for recall types (1: means only free recall task with a motivational stimulus, 2 means cued recall task with a motivational stimulus, 3 means serial recall with a motivational stimulus and 4 means free, cued, and serial recalls with no motivational stimulus)

$\mathrm{O}=$ the second $\mathrm{O}$ stands for observing which type of words comes over which, that is abstract words are better recalled than content words or vice versa. The numbers in lower case stand for $(1=$ abstract words, and $2=$ concrete words, and more generally retrieved and non-retrieved words), $(+)$ means the possibility that number of recalled words increases when a motivational stimulus is provided and (-) means the possibility that number of recalled words decreases when the motivational stimulus is not provided.

The three first groups were compared to group 4 to see first if words recall was correlated with motivation and then to see if motivation affected word recalling. The independent variable was 


\section{Examining the Effect of Motivation on Short-term Memory Recalling of Arabic Abstract and Concrete Words Using Free, Cued, and Serial Recall Paradigms}

the motivational stimulus - represented by one recall trail, that is recalling only either freely, with supportably (with cues), or serially [as compared to those who recalled the words freely], supportably, and serially. On the other hand, the dependent variable was the number of recalled abstract and concrete words in non-motivated and motivated groups.

\section{PROCEDURE}

Between 01.02.2014 and 01.03.2014, the study was conducted and all the following procedures were arranged and followed.

Data collection: an observation sheet for documenting the observed effects was designed where the subjects were first provided with a list of 20 words and asked to classify them into both abstract and concrete words. Before that, the students were provided with very basic information about the differences between abstract and concrete words. Moreover, they were introduced with related terms to classification process: concreteness, image ability, meaningfulness (Paivio Norms), and age of acquisition, (MRC Psycholinguistic Database, 2013). Having done that, the list of words was presented to the students using three methods:

1. Auditory methods: the administrator of the research reads the words aloud to the students;

2. Visual method: the administrator of the research presents the list of words to the student using an Over-head Projector (OHP) and PowerPoint slides where each word is presented as a card (pictures are may be provided next to each word); and

3. Writing method: the administrator of the research asks the students to read the words aloud and write them from the over-head projector in the paper-notes they are provided with.

The next step was asking the students to start recalling the words they can recall from both abstract and concrete words. Of course, the same procedure will be followed to the four groups with following differences:

1. Group one attempted only free recall (low attention level);

2. Group two attempted only cued recall (low attention level);

3. Group three attempted only serial recall (moderate attention level); and

4. Group four attempted free, cued and serial recalls (high attention level).

Authenticity: the students were informed by their instructor and were given the freedom to take part or not before being the subjects of the study. Having agreed, the students were assured to have full authenticity about the collected data and restricting its use for research purposes only. Needless to say, all the above procedures were officially documented using a consent form signed by each student confirming his free willingness to participate in the study. 


\section{Examining the Effect of Motivation on Short-term Memory Recalling of Arabic Abstract and Concrete Words Using Free, Cued, and Serial Recall Paradigms}

Measures administration: the two used measures were administered by the instructor of the course after being trained by the one of the researchers. The instructor was provided with all kinds of instructions that should be followed (detailed procedural issues can be seen in the appendix).

Time and environment of the measurement tools: the study was conducted at the College of Languages and Translation, King Saud University, Riyadh, Kingdom of Saudi Arabia. Each student was called individually into a well-prepared classroom with comfortable chairs, overhead projector, good air conditioning, and lightening. The used time for all the above described steps to be performed was about 26 minutes ( 4 minutes for each for those who were assigned to recall 20 words, and 2 minutes for each for those who were assigned to recall only 10 words).

Administering: the following steps were followed for administering the measurement tools in this study:

1. the administrator of the research provides the students with the list of 20 words requesting them to classify them into two lists: abstract and concrete words;

2. the administrator of the research collects the words' lists from the students;

3. the administrator of the test makes sure that none of the students has any words lists remaining with them;

4. the administrator of the test reads the list of words aloud (abstract-concrete or concreteabstract) to the students;

a. the students are requested to say the words which they can recall;

b. the administrator of the research documents the recalled words in both cases; and

5. the administrator of the research presents the words to the students using an over-head projector (OHP) requesting them to:

a. read them silently;

b. read them either aloud, finger pointing or lips-moving; and finally

c. write them down

- the students are requested to note down the words they could recall

Assessing: the researchers but not the administrator of the research (the instructor of the course) does the calculations for the following:

1. Number of recalled abstract words as opposed to number of recalled concrete ones.

Recall prompts: firs letter prompt, miming and or sign-language in addition to semantic associations were provided in some cases (see appendix for more details).

Preliminary analysis steps: Using the $17^{\text {th }}$ version of SPSS (Statistical Package for Social Sciences), both descriptive and referential statistics tools were used to test proposed hypotheses in this study. 


\section{RESULTS}

$17^{\text {th }}$ version of SPSS (Statistical Package for Social Sciences) was used for the statistical analysis of the collected data. Both descriptive and referential statistics were used where different yet suitable statistical tools were used from each to serve the purposes of the study. Table (6) below presents the used type of statistics, the selected tool and performed function. As a reminder for the proposed hypotheses in this study, they are:

3. Does motivation affect short memory recall?

b. Do the participants in the motivated group recall more words than do their counterparts who are not motivated?

4. Is there a correlation between motivation and memory recall of Arabic abstract and concrete words?

Table 6: summary of the statistical tools used in analyzing the data of this study

Statistics type

Descriptive

Statistics

\section{Inferential}

Statistics
SPSS tool(s)

Frequency

Mean

Standard Deviation

Frequencies: graphs

Pearson
Cronbach Alpha
Correlate: Bivariate

Graphs: scatter-plot
Purpose of use

Total number of recalled words

Total number of recalled abstract words

Total number of concrete words

Observed effects

The central location of the recalled words in free, cued, and serial recall paradigms

Measuring variability among recalled words in free, cued, and serial recall paradigms

Description and comparisons purposes

Reliability and validity issues

Reliability

Getting the correlation coefficient and degree of significance and deciding on whether there is a relationship or not between the two tested variables Seeing in clearer way the correlation between the two tested variables and ascertaining the presence or absence of relationship between the two tested variables

There were 36 participants in this study, divided into two groups. Group 1 acted as three groups where they performed free, cued and serial recall paradigms at the same time. Group 2 was divided into 3 groups, 9 in each where each group consisting of 9 students performed only one recall type. Percentages of total recalled Arabic abstract and concrete words in both groups are presented comparatively in figure 3 below. 
Figure 4: Comparison of the performance of one (A) and three groups (B) in three recall types

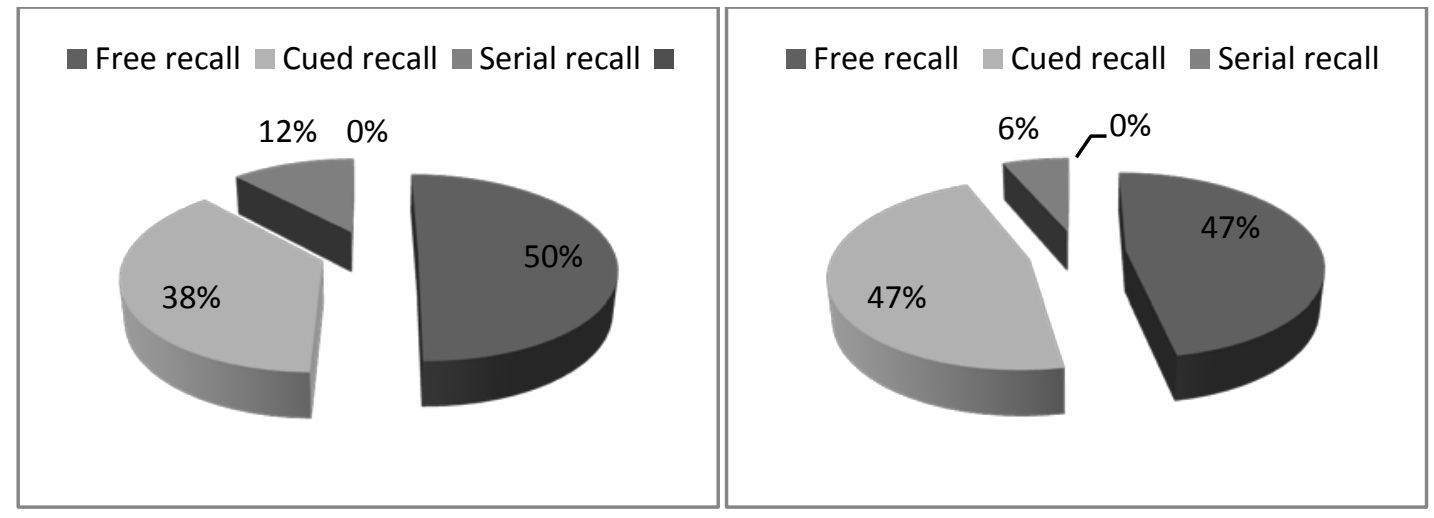

Both pie charts can be read counterclockwise. The pie chart to the right side presents the percentages of the three groups (the control group) $(9+9+9=27)$ and the pie chart to the left side presents the percentages of the experimental group. In both pie charts, free recall is the highest and serial recall is lowest. The percentage of experimental group (50) is insignificantly higher than the percentage of the control group (47\%). On the other hand, the percentage of the control group (47\%) is higher than the percentage of the experimental group (38\%) in cued recall paradigms. Similar to free recall paradigms where the percentage is higher in the experimental groups than in the control group so is it in the serial recall paradigms (12\%) for the former and (6) for the latter. This very early statistics gives us an impression that there might be a [correlation] between motivation and short memory recall of Arabic abstract and concrete words though the differences in percentages between two groups are not statistically different.

Detailed statistical results for the recalled Arabic abstract and concrete words in the control and experimental groups are shown in figures 4-5 below.

Figure 5 (A): Comparison of recalled words in different performed tasks of free, cued, and serial recall paradigms

\begin{tabular}{|c|c|c|c|c|c|c|}
\hline \multicolumn{7}{|l|}{25} \\
\hline \multicolumn{7}{|l|}{20} \\
\hline \multicolumn{7}{|l|}{15} \\
\hline \multicolumn{7}{|l|}{10} \\
\hline 5 & & & & & & \\
\hline 0 & $\begin{array}{l}20 \text { words } \\
\text { list }\end{array}$ & $\begin{array}{c}10 \text { words } \\
\text { list }\end{array}$ & $\begin{array}{c}\text { Abstract } \\
\text { words } 10 \\
\text { list }\end{array}$ & $\begin{array}{c}\text { Concrete } \\
\text { words } 10 \\
\text { list }\end{array}$ & $\begin{array}{c}\text { Abstract } \\
\text { words } 5 \\
\text { list }\end{array}$ & $\begin{array}{c}\text { Concrete } \\
\text { words } 5 \\
\text { list }\end{array}$ \\
\hline Free recall & 20 & 10 & 10 & 10 & 5 & 5 \\
\hline Cued recall & 15 & 7 & 7 & 7 & 3 & 3 \\
\hline Serial recall & 5 & 2 & 2 & 3 & 1 & 1 \\
\hline
\end{tabular}


Figure 6 (B): Comparison of recalled words in different performed tasks of free, cued, and serial recall paradigms

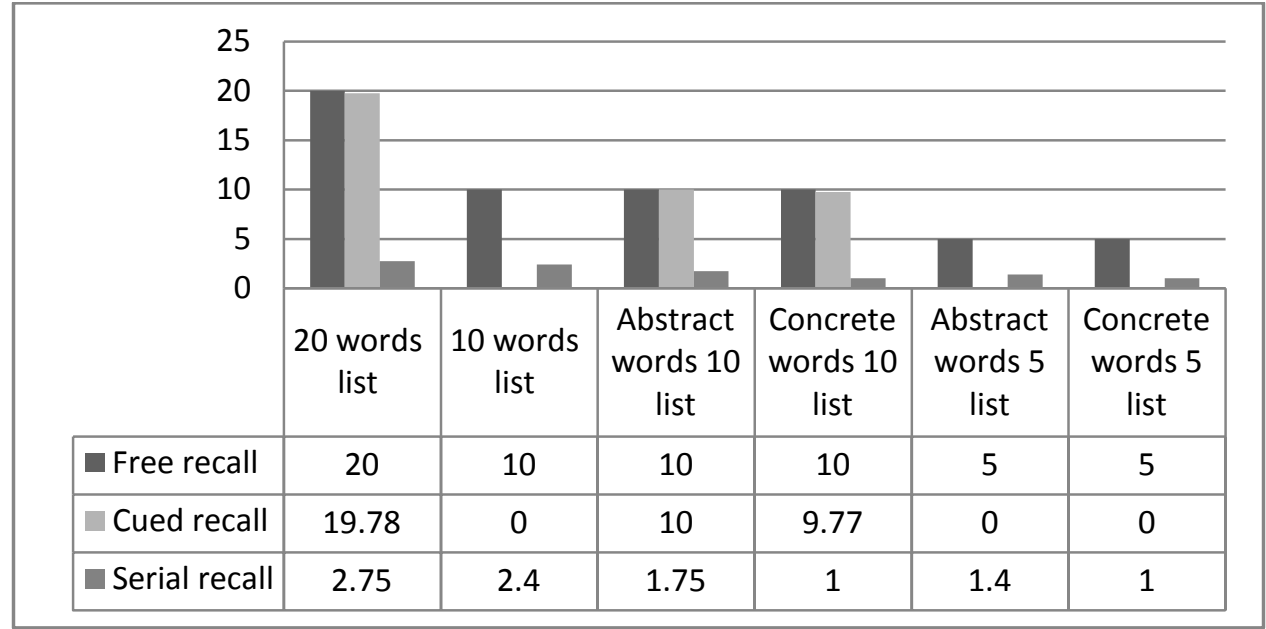

Figure 4 presents results for the experimental group whereas figure 5 presents results for the control group. In both control and experimental groups, the whole number of words was fully retrieved in free recall paradigms. In cued recall paradigms, the mean for the number of the recalled words is minimally less in the experimental group than the number of the recalled words in the control group (15) for the former and (19.78) for the latter. As for serial recall, it is surprisingly higher in the experimental group than that in the control group (5) for the former, and only (2.75) for the latter. These current results might indicate either a negative correlation or zero correlation as the differences in descriptive statistics are not significantly different between the results of short memory recall and motivation.

It was also proposed in our study that abstract words are better recalled than concrete ones in free, cued and serial recall paradigms be it with or without motivational stimulus. Statistical results for this claim are shown in figures 6-7) below.

Figure 7 (A): Abstractness, Concreteness, or Zero Effect?

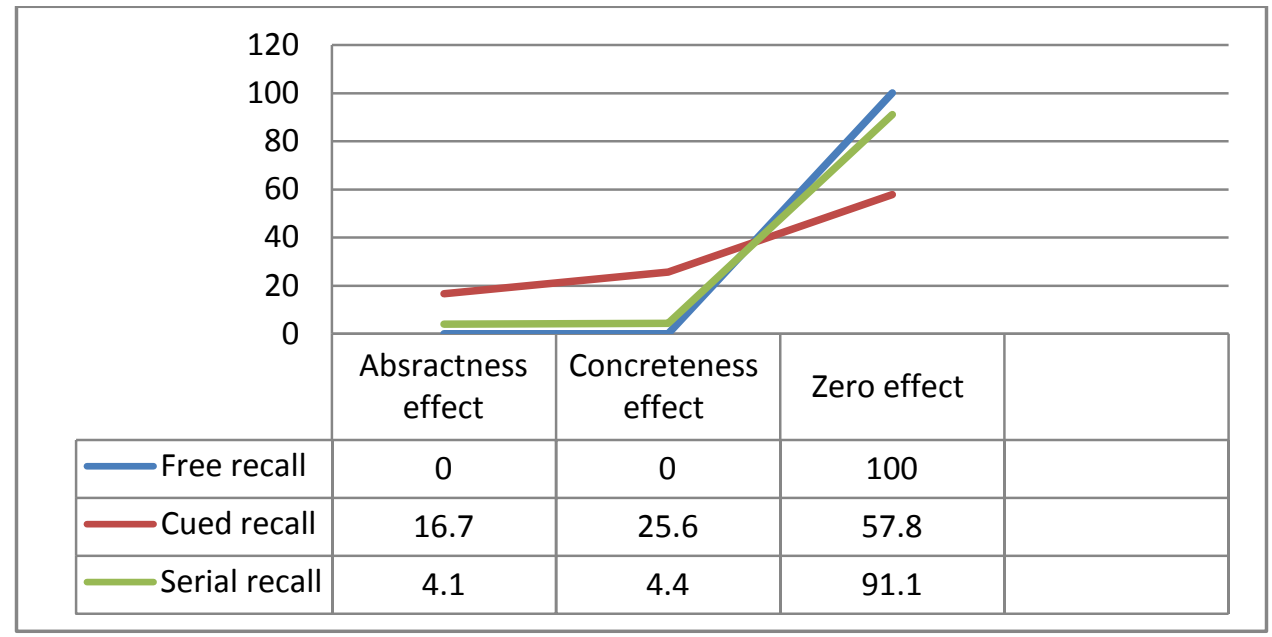


Figure 8 (B): Abstractness, Concreteness, or Zero Effect?

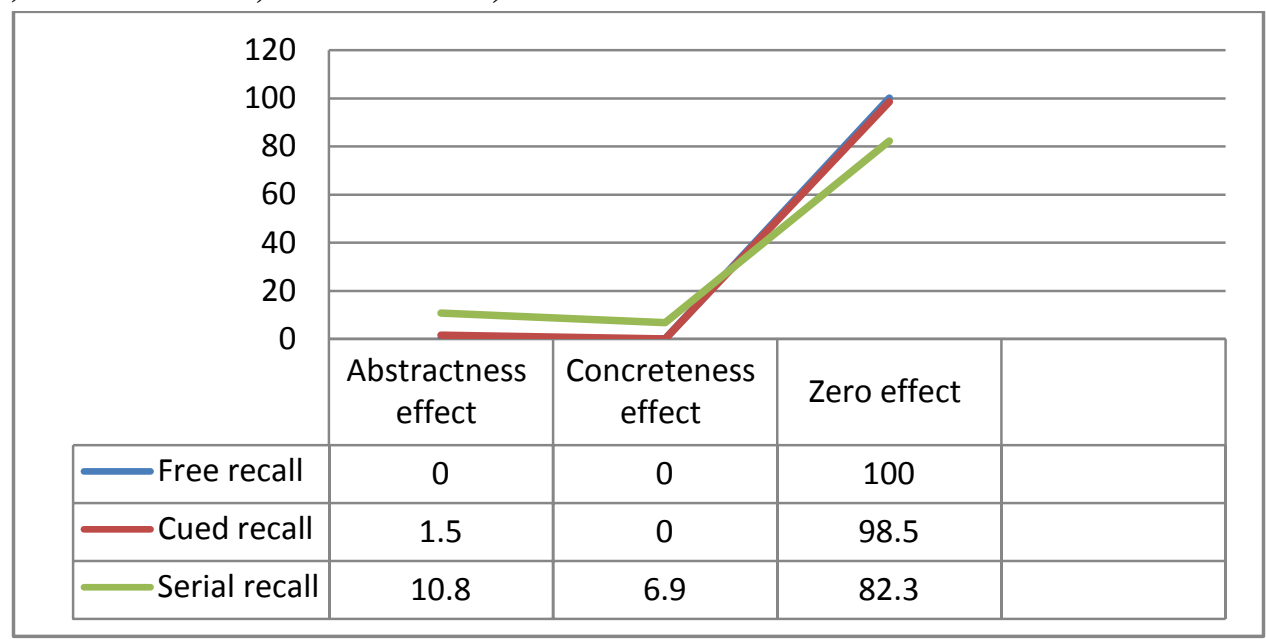

First, it should be noted that figure 6 presents results for the experimental group and figure 7, on the other hand, presents results for the control group. According to the two figures, in both control and experimental groups (with and without motivational stimulus) the effect is neither abstract (advantage of abstract words over concrete ones) nor concrete (advantage of concrete words over abstract ones), it is rather zero effect (identical number of recalled Arabic abstract and concrete words).

Both abstractness and concreteness effect remained stable and zero effect went up to (100) in free recall paradigms in the experimental and control groups.

In cued recall, there is a considerable sudden change where abstractness effects went up from (1.5) in the control group to (16.7) in the experimental group. Similarly, there is also a fast negligible change in the case of concreteness effect which picked up from (0) in the control group to (25.6) in the experimental group. Besides, there is a sharp substantial decline in the case of zero effect which deteriorated to (57.8) in the experimental group before it was (98.5) in the control group. This means clearly motivation increases recalled number of Arabic abstract and concrete words though the increase rate is slightly considerable.

In the case of serial recall paradigms, abstractness effects dropped gradually down to (4.1) in the experimental group. Similarly, concreteness effect did down to (4.4) before it was less than (7). On the other hand, zero effect increased gradually to (91.1) in the experimental group before it was only (82.3) in the control group.

To conclude, in spite of the gradual yet significant changes in the results between the two groups, it is still too early to decide whether short memory recall of words is correlated with motivation or whether the motivational stimulus affects short memory recall or not. 


\section{Examining the Effect of Motivation on Short-term Memory Recalling of Arabic Abstract and Concrete Words Using Free, Cued, and Serial Recall Paradigms}

More descriptive statistics will help us to reach a solid decision about this issue before starting the analysis of referential statistics. Comparisons of observed effects in both the experimental and control groups for the three types of recall are presented in figures 8-11.

Figure 9: Effects comparison in free recall paradigms

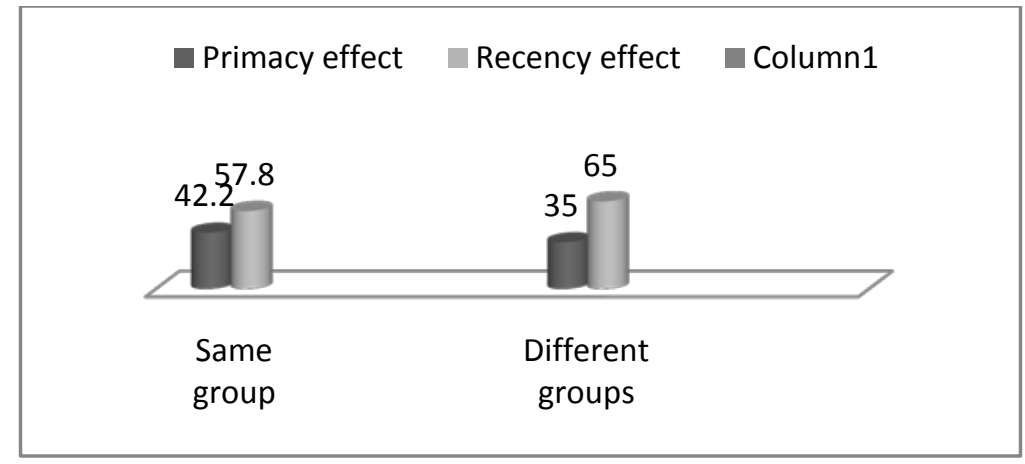

The above bar chart presents comparatively the observed effects in control and experimental groups in free recall paradigms. There were two observed effects in free recall paradigms, namely primacy and recency effects. It can be seen clearly that in both groups recency is the most popular effect, while primacy is the least popular one.

At the beginning, primacy effect is more frequent in the experimental group than the primacy effect in the control group. It goes up in the former to (42.2) and then goes gradually down in the latter to exactly (35). On the hand, recency effect is more frequent in the control group than the recency effect in the experimental group. It picked up in the former to exactly (65) and then slips back in the latter to less than (58).

Thus, recency effect is generally more frequent than the primacy effect. Also, while primacy effect is higher in the experimental group and lowers in the control group than the recency effect, recency effect is conversely higher in the control group and lower in the experimental group.

Figure 10: Effects comparison in cued recall paradigms

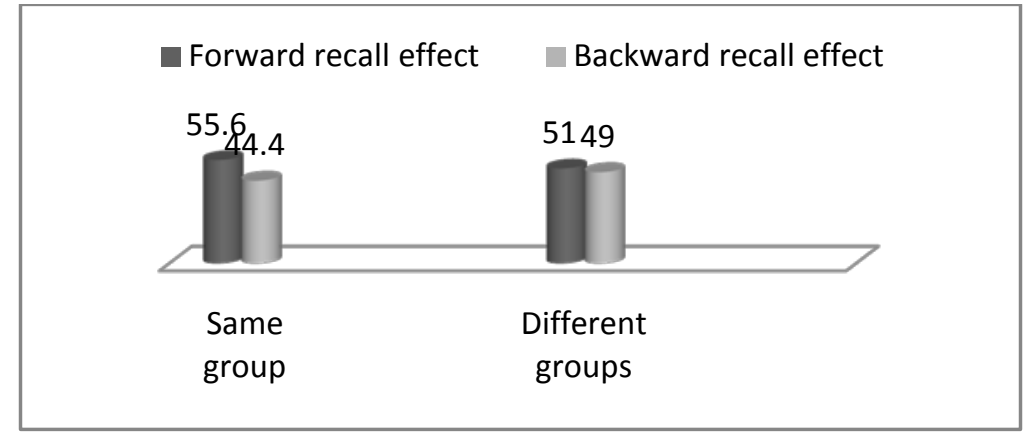

The above bar chart deals with observed effect in both experimental and control groups in cued recall paradigms. There were two observed effects in cued recall paradigms of Arabic abstract and concrete words, mainly forward and backward recalls. It is immediately apparent that 


\section{Examining the Effect of Motivation on Short-term Memory Recalling of Arabic Abstract and Concrete Words Using Free, Cued, and Serial Recall Paradigms}

forward recall effect is the most common observed effect and backward recall is least common observed effect.

To start, forward recall in the experimental group is more popular than it is in the control group. It improves to over (55) in the experimental group and stops at (51) in the control group. In comparison, backward recall in the experimental group is less popular than it is in the control group with only a slight change at the rate of less than (4). That is to say, it stops at less than (44) in the former and reaches (49) in the latter.

In conclusion, forward recall effect is generally more observed than backward recall effect during cued recall paradigms in both the experimental and control groups. Yet, forward recall effect has an advantage over backward recall effect in the experimental groups while the latter has an advantage over the former in the control group.

Figure 11 (A): Comparison of observed effects in serial recall paradigms

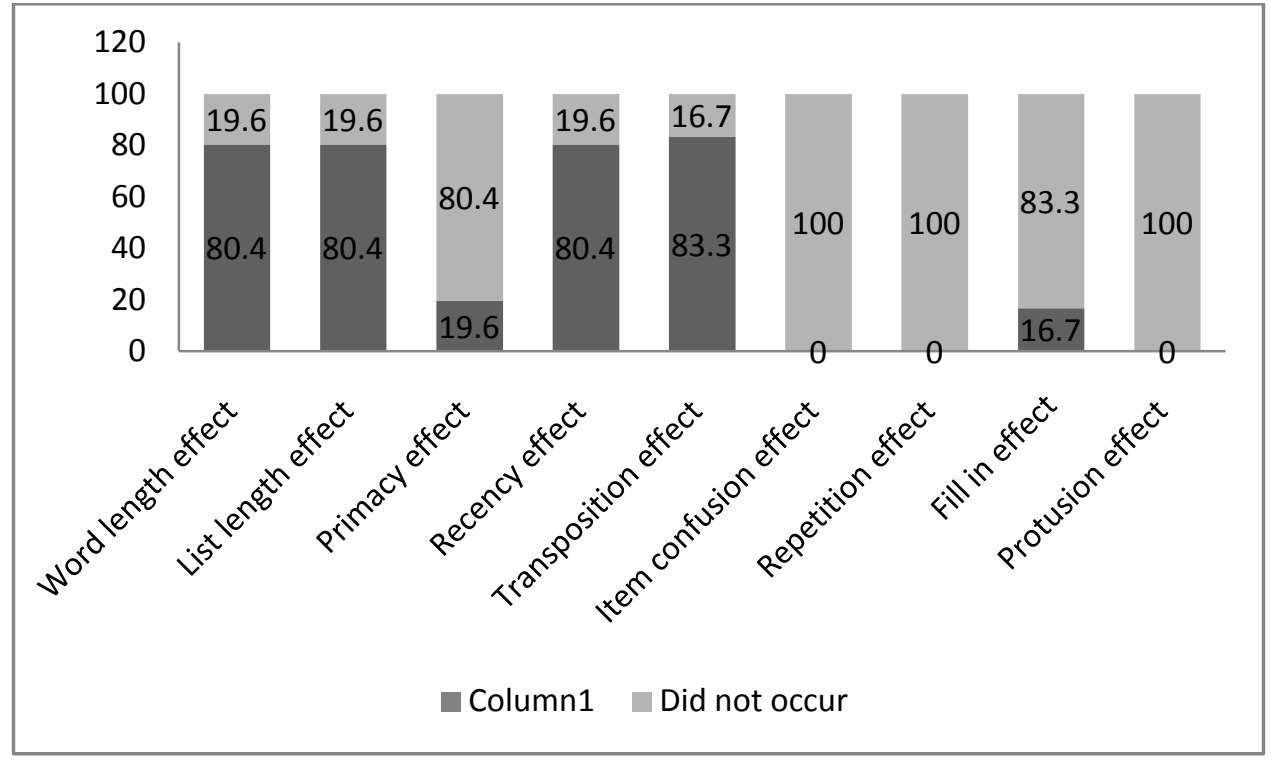


Figure 12 (B): Comparison of observed effects in serial recall paradigms

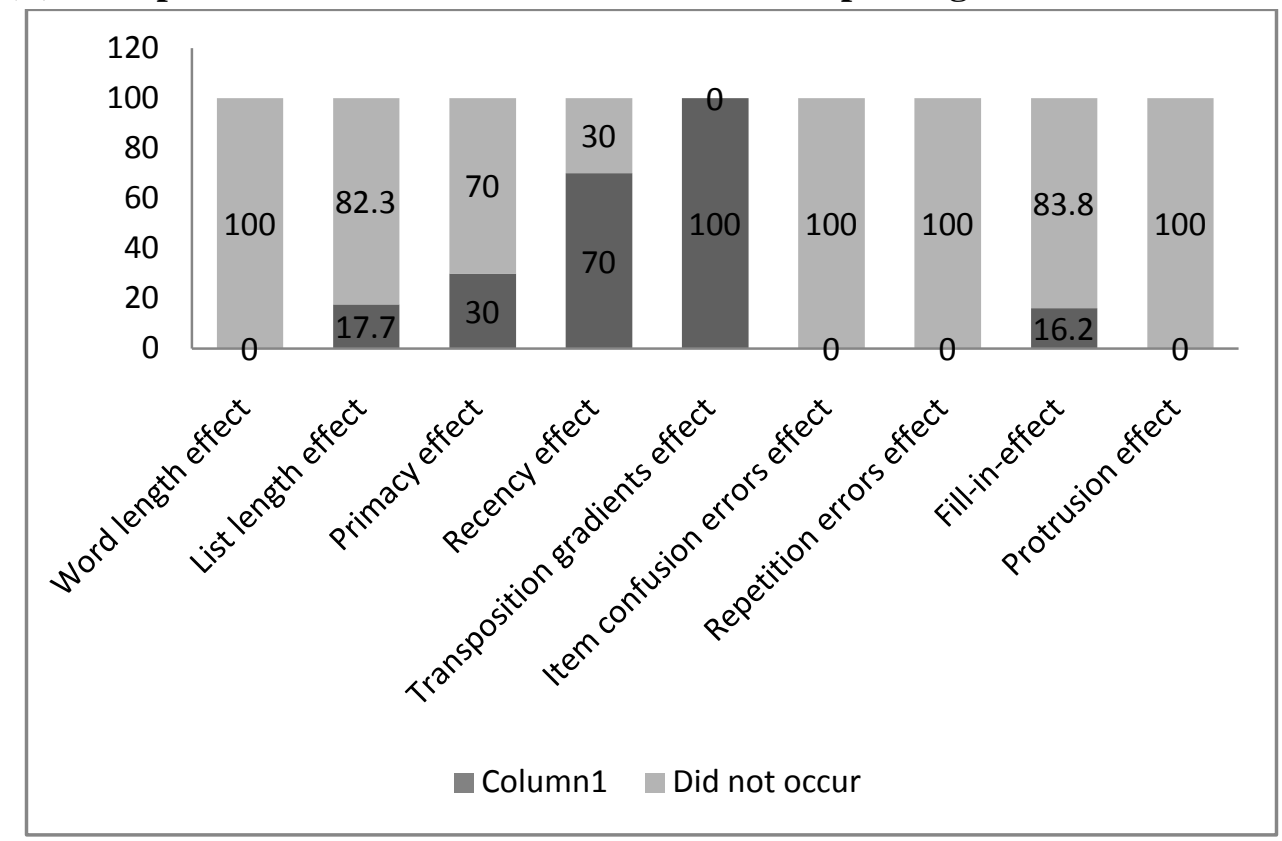

The above bar charts (10-11) show the observed effects during serial recall paradigms of Arabic abstract and concrete words for both experimental and control groups. While the first bar chart represents the experimental group, the second one represents the control group. There were nine pre-specified effects to be observed-as mentioned above in the bar charts during serial recall paradigms. Generally, there are three non-observed effects in the experimental group and four in the control group.

In the beginning, while there were three non-observed effects in the experimental group (item confusion error, repetition error and protrusion effects), there were four in the control group (the above mentioned three in addition to word length effect). Moreover, the most frequent occurring effect in both experimental and control groups was transposition gradients effect with being higher for the control group (100) as compared to less than (84) for the experimental group. On the other hand, the least frequent occurring effect for both groups again was the fill-in effect with a slight difference in favour of that for the experimental group (16.7) as compared to (16.2) for the control group.

Some major differences between the two groups in regard to the observed effect include that while word length effect did not occur at all in the control group, the occurrence rate climbs rapidly yet dramatically to over (80) and non-occurrence rate slips back sharply to less than (20). One more noticeable yet sudden change is that for list length effect. The occurrence rate bottomed out in the experimental group to less than (19) after it was over (82) in the control group. On the contrary, the non-occurrence rate rose considerably yet quickly to over (80) in the experimental group after it was only less than (18) in the control group. 


\section{Examining the Effect of Motivation on Short-term Memory Recalling of Arabic Abstract and Concrete Words Using Free, Cued, and Serial Recall Paradigms}

To sum up, some of the pre-specified effects were not observed at all in both groups and some others were observed in both groups with a preference for the occurrence of the observed effect to the experimental group.

In order to reach solid yet better results for the proposed hypotheses in this study, referential statistics tools were used. The means and standard deviations of the independent variable (motivation) and dependent variable (recalled Arabic abstract and concrete words abbreviated to short recall memory) are presented below in table 7.

Table 7: Descriptive Statistics

\begin{tabular}{lcrr}
\hline \hline & Mean & Std. Deviation & $\mathrm{N}$ \\
\hline Short term memory recall & 1.7523 & .43218 & 440 \\
Motivation & 1.6614 & .47378 & 440 \\
\hline \hline
\end{tabular}

It can be clearly seen from the two means for the independent variable and the dependent variable that the mean for the former (M: 1.66) with a standard deviation of (SD: .47) is slightly lower than the mean for the latter (M: 175) with a standard deviation of (SD: .43). This clearly initially indicates a correlation between the two variables from one side and the effect of one variable on the other, mainly the independent one on the dependent one (motivation on shortterm memory recall). These above mentioned inferences are verified more in table 8 below.

\begin{tabular}{|c|c|c|c|}
\hline & & $\begin{array}{c}\text { Short term memory } \\
\text { recall }\end{array}$ & Motivation \\
\hline \multirow{3}{*}{$\begin{array}{l}\text { Short term memory } \\
\text { recall }\end{array}$} & Pearson Correlation & 1 & $.713^{* \pi}$ \\
\hline & Sig. (2-tailed) & & .000 \\
\hline & $\mathrm{N}$ & 440 & 440 \\
\hline \multirow[t]{3}{*}{ Motivation } & Pearson Correlation & $.713^{\pi \pi}$ & 1 \\
\hline & Sig. (2-tailed) & .000 & \\
\hline & $\mathrm{N}$ & 440 & 440 \\
\hline
\end{tabular}

A Pearson product-moment correlation coefficient was computed to assess the relationship between motivation (one recall trail, that is recalling only either freely, supportably (with cues), or serially [as compared to those who recalled the words freely, supportably, and serially) and short-term memory recall (recalled Arabic abstract and concrete words). There was a positive correlation between the two variables, $\mathrm{r}=0.713, \mathrm{n}=440, \mathrm{p}=0.000$, with $\mathrm{R}^{2}=.508$. A scatterplot summarizes the results in Figure 12. Overall, there was a moderate, positive correlation between motivation and short-memory recall. Increases in the motivational stimulus were correlated with increases in retrievable Arabic abstract and concrete words (short-term memory recall). 
Figure 13: Direction of correlation between motivation and short memory recall

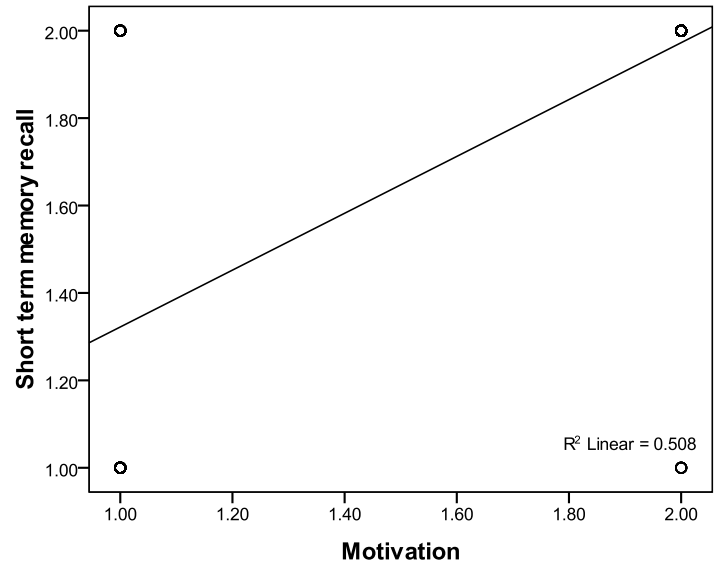

The mean number of motivation at these memory recall paradigms was $1.66(\mathrm{SD}=.47)$ and the short-term memory recall had a mean recall rating of $1.75(\mathrm{SD}=.43)$. Pearson's correlation supported the research hypothesis that those participants with a motivational stimulus tended to recall slightly more Arabic abstract and concrete words, whereas those participants with no motivational stimulus would tend to recall slightly less Arabic abstract and concrete words, $\mathrm{r}=$ $.713, \mathrm{p}<0.01$.

To conclude, the value of $\mathrm{R}$ is 0.713 . This is a moderate positive correlation, which means there is a tendency for high $\mathrm{X}$ variable scores go with high $\mathrm{Y}$ variable scores (and vice versa).The value of R2, the coefficient of determination, is 0.508.The P-Value is $<0.00001$. The result is significant at $\mathrm{p}<0.01$.

\section{DISCUSSION}

The results of this study were partially on contrary to the initial expectations. We examined the effect of motivation on short-term memory recall of Arabic abstract and concrete words using free, cued, and serial recall paradigms. However, we raised two study questions where the statistical analysis refuted partially our first hypothesis (effect of motivation on short-term memory recall) and supported on the other hand our second hypothesis (correlation of motivation to short-term memory recall). The answers of the two raised questions are presented below in relation to the presented introduction, reviewed studies and the statistical analysis.

The first question was to know whether motivation affects short memory recall or not? For that matter we proposed that the participants in the motivated group will recall more words than will their counterparts who were not motivated. The motivation stimulus was that while the participants in the experimental group were required to recall the list of words performing three types of recall consecutively, those in the control group (three groups) were required to perform only one type of recall. The statistical analysis indicated that the percentage of the retrieved words by the control group was slightly lower than that of the experimental group in the case of 


\section{Examining the Effect of Motivation on Short-term Memory Recalling of Arabic Abstract and Concrete Words Using Free, Cued, and Serial Recall Paradigms}

free and serial recall paradigms. In other words, while the percentage of the retrieved words during frees recall paradigm was only (47\%) for the control group, it went slightly up to reach (50\%) for the experimental group. On the other hand, while the percentage of the recalled words during serial recall paradigm was only (6\%) for the control group, it was as two times as that of the control group for the experimental group (12\%). Our expectation was that the control group participants will perform noticeably better than those of the experimental group. This view was supported by that motivation will positively affect their performance yet negatively affect the performance of their counterparts. In spite of this, the effect of motivation on the ability of the learners to recall Arabic abstract and concrete words was clear in the case of cued recall. The percentage of the retrieved words by the control group during cued recall was clearly though not greatly higher than that of the experimental group: (47\%) for the former and only (38\%) for the latter.

With reference to (figure 2: types of motivation p.3), motivation type can make a difference in the expected results of the intended goal. In other words, using a physiological motivation would, to a great extent, result in a different output from that when using a cognitive motivation or a social motivation. Our motivation stimulus was only that a certain group of students were trained to recall the list of words using three recall types and the motivation for the others is that each group of student will only recall the list of words using one recall type. Taking this into consideration, we think that such a selected motivation stimulus was not that valuable to push them enough to perform better and excel their counterparts. Instead, those who were requested to recall using the three types of recall were indirectly motivated believing that their cognitive abilities are higher than those of their counterparts. Moreover, they programmed themselves assuming that they were selected to do so because they were cognitively better than those who were requested to recall using only a recall type. Consequently, we assume that in addition to the above mentioned types of motivation, there could be also direct and indirect motivation. Both of these types could be either positive or negative. It would be positive as in the case of the experimental group who assumed that their selection was due to their high cognitive abilities; though, this was not really considered as the selection of the participants was random. It would be negative if they have understood that they have been requested to do so as a punishment for them or that their level is low and intensive learning is required to raise their level up (see studies and views presented by: Monsell\& Driver, 2000; Psychology-Stanford, 2007; Richards, Daller, Malvern, Meara, Milton, \& Treffers-Daller, 2009; Sprenger, 1999; Takac, 2008; Yamagishi, Sato, Sato \& Imamura, 2012).

The second hypothesis was that there might be a correlation between motivation and memory recall of Arabic abstract and concrete words. Our statistical analysis approved the validity of this claim. The results indicated a correlation between the two variables from one side and the effect of one variable on the other, mainly the independent one on the dependent one (motivation on short-term memory recall). Say it differently, there was a positive correlation between the two 


\section{Examining the Effect of Motivation on Short-term Memory Recalling of Arabic Abstract and Concrete Words Using Free, Cued, and Serial Recall Paradigms}

variables, $\mathrm{r}=0.713, \mathrm{n}=440, \mathrm{p}=0.000$, with $\mathrm{R} 2=.508$. There was a moderate, positive correlation between motivation and short-memory recall.Pearson'scorrelation supported the research hypothesis that those participants with a motivational stimulus tended to recall slightly more Arabic abstract and concrete words; whereas, those participants with no motivational stimulus tended to recall slightly less Arabic abstract and concrete words, $r=.713, p<0.01$.

The results of our study whether refuting our hypotheses or supporting them were in queue with previous studies. For instance, in the case of the view that motivation does greatly affect language learning and more specifically word recall, consider those studies conducted by (Ngaosuvan, 2004; Ngaosuvan \& Mantyla, 2005; Oller and Perkins (as cited in Baker, 1996 \& and UKEssays, 2014). On the other hand, studies which supported or reached result that the effect of motivation can be slight in some situations include but not limited to those conducted by (UKEssays, 2014; UKEssays, 2014).

\section{CONCLUSIONS}

The current study attempted one of the memory processes, mainly recall in relation to one of the factors affecting memory recall-motivation. More specifically, we examined effect of motivation on short-term memory recall of Arabic abstract and concrete words using free, cued, and serial recall paradigms along with the possibility of investigating the correlation of motivation to short-term memory recall. A four group quasi-experimental randomized design where a total number of 36 of Arab natives took part in this study. They were divided into two groups of 9 where 9 was dealt as the experimental group (performing free, cued and serial recall paradigms) and the other 27 were divided into three groups where each group performed only a recall type. The three groups were dealt as the control group. The independent variable was the motivational stimulus - represented by one recall trail, that is, recalling only either freely, with cues supportably or serially [as compared to those who recalled the words freely, supportably, and serially]. On the other hand, the dependent variable was the number of recalled abstract and concrete words in non-motivated and motivated groups. Our findings indicated that motivation effect on short-term memory recall of Arabic abstract and concrete words was not significant especially in the case of free and serial recall paradigms. The participants in the experimental group and who were not motivated recalled slightly more words than those which were recalled by the participants who were motivated. In spite of this, our statistical analysis indicated that there is a correlation between motivation and short-term memory recall. That is to say, Pearson's correlation supported the research hypothesis that those participants with a motivational stimulus tended to recall slightly more Arabic abstract and concrete words; whereas, those participants with no motivational stimulus tended to recall slightly less Arabic abstract and concrete words, $\mathrm{r}$ $=.713, \mathrm{p}<0.01$. 


\section{IMPLICATIONS}

This study has a cognitive implication. In spite of the fact that motivation has approved its positivity towards education in general but the selection of motivational stimulus seems to decide the fulfillment of this positive side. In the case of our research, for instance, we assume that the main reason for the insignificant difference between the motivated and non-motivated groups is due to the inappropriate selection of the motivational stimulus.

\section{LIMITATIONS AND FUTURE WORK}

This study has one limitation in relation to research methodology. We have already mentioned in the introductory part that motivation has a number of types and can be divided on the basis of various aspects. We introduced physiological motivation, cognitive motivation, and social motivation where our motivational stimulus falls in the second one. We assume that if our motivational stimulus was one of the following one; our results would have been more plausible and supportive to our hypotheses especially in the sense of investigating the effect of motivation on short-term memory recall of Arabic abstract and concrete words.

1. Cognitive stimuli:

a. Bonus marks;

b. Creativity achievement certificate;

2. Physiological stimuli:

a. A pedagogical book (text book):

b. A literature piece;

c. Any suitable gift;

3. Social stimuli:

a. Announcing the names of the list of students on university board; and

b. Introducing the group of the students in the class as a creativity group.

Future research should take into consideration other factors affecting memory recall. These factors include: attention, interference, context, state-dependent memory, gender, food consumption, physical activity and trauma and brain exposure.

\section{ACKNOWLEDGMENTS}

We would like to deeply thank the Research Centre in the College of Languages and Translation Studies and the Deanship of Scientific Research for their financial support of this project under (Cognitive Linguistics Research Group), King Saud University, Riyadh, Kingdom of Saudi Arabia. 


\section{REFERENCES}

Aitchison, J. (1987). Words in the Mind: An Introduction to the Mential Lexicon . Cambridge: Basil Blackwell.

Atkinson, R. C., \& Shiffrin, R. M. (1968). Human memory: A proposed system and its control processes. In K. W. Spence, \& J. T. Spence (Eds.), he Psychology of learning and motivation: Advances in research and theory (Vol. 2, pp. 90-191).

Baddeley, A. (1999). Essentials of Human Memory. East Sussex: Psychology Press Ltd.

Baddeley, A. D. (2004). The Psychology of Memory. In A. Baddeley, M. Kopelman, \& B. Wilson (Eds.), The Essential Handbook of Memory Disorders for Clinicians. New York: John Wiley \& Sons, Ltd.

Baker, C. (1996). Foundations of Bilingual Education and Bilingualism: Bilingual Education and Bilingualism. Bristol: Multilingual Matters.

Benjamin, A. S., \& Ross, B. H. (Eds.). (2007). The Psychology of Learning and Motiviation: Advances in Research and Theory (Vol. 48). Amsterdam: Elsevier Inc.

Bower, G. H. (1969). Chunks as interference units in free recall. Journal of Verbal Learning and Verbal Behavior, 8(5), pp. 610-613.

Bower, G. H. (Ed.). (1991). The Psychology of Learning and Motiviation (Vol. 27). San Diego: Academic Press, Inc.

Byrne, J. H. (Ed.). (2003). Learning \& Memory. New York: Macmillan Reference.

Conway, M. A. (Ed.). (1997). Cognitive models of memory . Cambridge : MIT Press .

Cowan, N. (2005). Working memory capacity. New York : Psychology Press Taylor \& Francis Group, LLC.

Dukes, W. F., \& Bastian, J. (1966). Recall of abstract and concrete words equated for meaningfulness. Journal of Verbal Learning and Verbal Behavior, 5(5), pp. 455-458.

Eichenbaum, H. (2002). The cognitive neuroscience of memory : an introduction. New York: Oxford University Press .

Ellis, R. (1992). Second Language Acquisition \& Language Pedagogy Multilingual Matters . Bristol : Multilingual Matters.

Ellis, R. (1997). Second Language Acquisition . Oxford : Oxford University Press.

Ellis, R. (2012). Language teaching research and language pedagogy. West Sussex: WileyBlackwell.

Ellis, R. (Ed.). (2005). Planning and task performance in a second language. John Benjamins Publishing Company.

Ellis, R., Loewen, S., Elder, C., Erlam, R., Philp, J., \& Reinders, H. (2009). Implicit and Explicit Knowledge in Second Language Learning, Testing and Teaching. Bristol: Multilingual Matters.

Faust, M. (Ed.). (2012). The Handbook of the Neuropsychology of Language. Malden: Blackwell Publishing Ltd. 


\section{Examining the Effect of Motivation on Short-term Memory Recalling of Arabic Abstract and Concrete Words Using Free, Cued, and Serial Recall Paradigms}

Fliessbach, K., Weis, S., Klaver, P., Elger, C. E., \& Weber, B. (2006). The effect of word concreteness on recognition memory. NeuroImage, 32(3), 1413-1421. doi:http://dx.doi.org/10.1016/j.neuroimage.2006.06.007

Foster, J. K. (2009). Memory: A Very Short Introduction. Oxford : Oxford University Press .

Fuchs, A. (2014). Motivation. Retrieved from SpringerReference: http://www.springerreference.com/docs/html/chapterdbid/83606.html

Greene, J. (1987). Memory, Thinking and Language: Topics in cognitive psychology. London: Methuen .

Kliegel, M., McDaniel, M. A., \& Einstein, G. O. (Eds.). (2008). Prospective memory : cognitive, neuroscience, developmental, and applied perspectives. New York : Lawrence Erlbaum Associates Taylor \& Francis Group.

Mace, J. H. (Ed.). (2007). Involuntary memory. Malden: Blackwell Publishing Ltd.

Mense, B. R., Debney, S. J., \& Druce, T. M. (2006). Short-term auditory memory activities. Camberwell: ACER Press.

Menzel, R. (Ed.). (2008). Learning and Memory . AP.

Mestres-Missé, A., Münte, T. F., \& Rodriguez-Fornells, A. (2009). Functional neuroanatomy of contextual acquisition of concrete and abstract words. Journal of Cognitive Neuroscience, 21(11), pp. 2154-71.

Monsell, S., \& Driver, J. (2000). Control of Cognitive Processes. MIT Press.

MRC-Psycholinguistic-Database-Editors. (1987). MRC Psycholinguistic Database: Dict Utility Interface. Retrieved from MRC Psycholinguistic Database: http://websites.psychology.uwa.edu.au/school/MRCDatabase/uwa_mrc.htm

Ngaosuvan L., Mäntylä T. Rewarded remembering: Dissociations between self-rated motivation and memory performance: Scandinavian Journal of Psychology, vol.46 , n 4, 2005 , p.323-330.

Ngaosuvan, L. (2004). MOTIVATION AND EPISODIC MEMORY PERFORMANCE. Umeå: Department of Psychology, Umeå University, Umeå, Sweden.

Noordman-Vonk, W. (Ed.). (1979). Retrieval from Semantic Memory. New York : SpringerVerlag Berlin Heidelberg .

Oller, K. B., \& Eliers, R. E. (Eds.). (2002). Child Language and Child Development: Multilingual-Multicultural Perspectives: Language and Literacry in Bilingual Children . Clevedon: Multilingual Matters Ltd.

Oxford-Index-Editors. (2014). Motivation. Retrieved from Oxford Index: http://oxfordindex.oup.com/view/10.1093/acref/9780199234899.013.4203?rskey=4vq6R T\&result $=1$

Parker, A., Wilding, E. L., \& Bussey, T. J. (Eds.). (2002). The Cognitive Neuroscience of Memory. Hove: Psychology Press.

Pickering, S. J. (Ed.). (2006). Working memory and education . Academic Press.

Prior, M. R., Cumming, G., \& Hendy, J. (1984). Recognition of abstract and concrete words in a dichotic listening paradigm. Cortex; a Journal Devoted to the Study of the Nervous 


\section{Examining the Effect of Motivation on Short-term Memory Recalling of Arabic Abstract and Concrete Words Using Free, Cued, and Serial Recall Paradigms}

System and Behavior, 20(1), 149-157. Retrieved from http://search.proquest.com/docview/81071377?accountid=142908

Psychology-Dictionary-Editors. (2012). What is motivation? Retrieved from Psychology Dictionary: http://psychologydictionary.org/motivation/

Psychology-Stanford. (2007). Encoding and Retrieval from Long-Term Memory. In PsychologyStanford, Cognition (pp. 192-238). Stanford: Psychology Stanford.

Randall, M. (2007). Memory, Psychology and Second Language Learning. Amsterdam: John Benjamins Publishing Company.

Richards, B., Daller, M. H., Malvern, D. D., Meara, P., Milton, J., \& Treffers-Daller, J. (Eds.). (2009). Vocabulary Studies in First and Second Language Acquisition. New York : Palgrave Macmillan.

Salsbury, T., Crossley, S. A., \& McNamara, D. S. (2011). Psycholinguistic word information in second language oral discourse. Second Language Research, 27(3), 343-360. doi:http://dx.doi.org/10.1177/0267658310395851

Sprenger, M. (1999). Learning \& Memory: the Brain in Action . Alexandria : Association of Supervision \& Curriculum Development .

Takac, V. P. (2008). Vocabulary Learning Strategies and Foreign Language Acquisition . Clevedon: Multilingual Matters Ltd.

UKEssays-Editors. (2014a). Effect Of Motivation On Short Term Memory Recall Psychology Essay. Retrieved from ukessays.co m: http://www.ukessays.co m/essays/psycho lo gy/effect-o f-mo tivatio n-o n-sho rt-term-memo ry-recall-psycho lo gy-essay.php

UKEssays-Editors. (2014b). Motivation In Second Language Learning English Language . Retrieved from ukessays.co m: http://www.ukessays.co m/essays/english-language/mo tivatio n-in-seco nd-language-learning-english-language-essay.php

UKEssays-Editors. (2014c). Promoting Motivation For Language Learning Through Autonomy Education. Retrieved from ukessays.co m: http://www.ukessays.co m/essays/educatio n/pro mo ting-mo tivatio n-fo r-language-learning-thro ugh-auto no my-educatio nessay.

UK-Essays-Editors. (2014d). The Effects Of Age And Motivation English Language. Retrieved from ukessays.co m: http://www.ukessays.co m/essays/english-language/the-effects-o fage-and-mo tivatio n-english-language-essay.php

UK-Essays-Editors. (2014e). The Motivation Towards Learning English English Language. Retrieved from ukessays.co m: http://www.ukessays.co m/essays/english-language/themo tivatio n-to wards-learning-english-english-language-essay.php

Walker, I., \& Hulme, C. (1999). Concrete words are easier to recall than abstract words: Evidence for a semantic contribution to short-term serial recall. Journal of Experimental Psychology: Learning, Memory, And Cognition, 25(5), 1256-1271. doi:10.1037/02787393.25.5.1256

West, W. C., \& Holcomb, P. J. (2000). Imaginal, semantic, and surface-level processing of concrete and abstract words: An electrophysiological investigation. Journal of Cognitive 
Neuroscience, $\quad$ 12(6), 1024-1037. $\quad$ Retrieved from http://search.proquest.com/docview/72554202?accountid=142908

Yamagishi, T., Sato, T., Sato, A., \& Imamura, T. (2012). Cognitive factors affecting free recall, cued recall, and recognition tasks in alzheimer's disease. Dementia and Geriatric Cognitive Disorders Extra, 2(1), 278-285. doi:http://dx.doi.org/10.1159/000341600

\section{APPENDIX}

Examining the Effect of Motivation on Short-term Memory Recalling of Arabic Abstract and Concrete Words Using Free, Cued, and Serial Recalling Paradigms

Group ( )Classification of abstract and concrete words Participant ( $\quad$ )

Note: This form is used to classify abstract and concrete words

Instructions:

1. Write:

A. No. (1) in the first column if the word has a concrete meaning

B. No. (3) in the first column if the word does not have a concrete meaning

C. No. (2) in the first column if you think that the word can have a concrete meaning, but you are not sure

2. Write:

A. No. (1) in the second column if you can imagine a clear picture of the word in your imagination

B. No. (3) in the second column if you cannot imagine any clear picture of the word in your imagination

C. No. (2) in the second column if you think that you can imagine but the word does not seem to have a clear picture to be imagined.

3. Write:

A. No. (1) in the third column if you think that the word has a clear meaning without any difficulty.

B. No. (3) in the third column if you think that the word does not have a clear meaning and may have a complex meaning and it is not easy to recall.

C. No. ( 2) in the third column if you think that the word looks simple and at the same time complex and difficult to understand.

4. Write:

A. Try to remember the year during your life time where you think you acquire the word. Note: Acquisition here means the first time in your life you feel that you can practice using the word. 
Examining the Effect of Motivation on Short-term Memory Recalling of Arabic Abstract and Concrete Words Using Free, Cued, and Serial Recall Paradigms

Classification Form

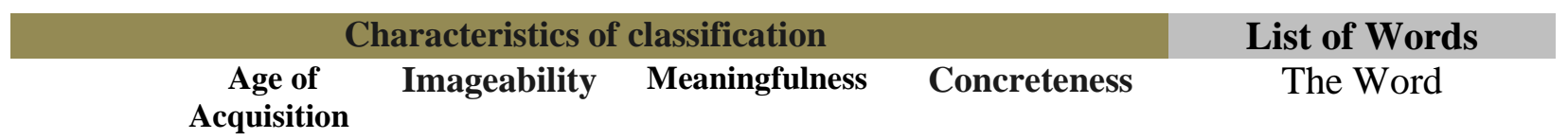

Inspiration
Human
Insight
Data
Body
Jinn
Paradise
Brain
Spirit
Poet
Charity
Conscience
Torment
Mind
Eyes
heart
Computer
Money
Fire
Happiness




\section{Examining the Effect of Motivation on Short-term Memory Recalling of Arabic Abstract and Concrete Words Using Free, Cued, and Serial Recalling Paradigms}

Participant (1)

(Free recall)

Group (A)

Note:

This form is used to record the oral recall(Please use here the five non-shaded words only).

Observed Effect
Recency effect

\section{Instructions:}

1. Please write in order the number of words that were recalled by the student. If the student remembers the next word or the word next to it, then, write the number in order. For example, if the student remembers the first word (heart) write (1) in the oval circle. If it is the second word (fire), write (2) in the oval circle and so on. Do not write anything for words that cannot be remembered by the student and leave the oval circle blank to mean that the student did not remember those word(s) within the list of words. 
Examining the Effect of Motivation on Short-term Memory Recalling of Arabic Abstract and Concrete Words Using Free, Cued, and Serial Recall Paradigms

\section{Examining the Effect of Motivation on Short-term Memory Recalling of Arabic Abstract and Concrete Words Using Free, Cued, and Serial Recalling Paradigms}
Participant (1)
(Free recall)
Group (A)

Note: This form is used to record recall by writing. (Please, use here the non-shaded five words only).

\begin{tabular}{|c|c|}
\hline Observed Effect & List of Words \\
\hline Recency effect Primacy effect & Abstract Words \\
\hline
\end{tabular}

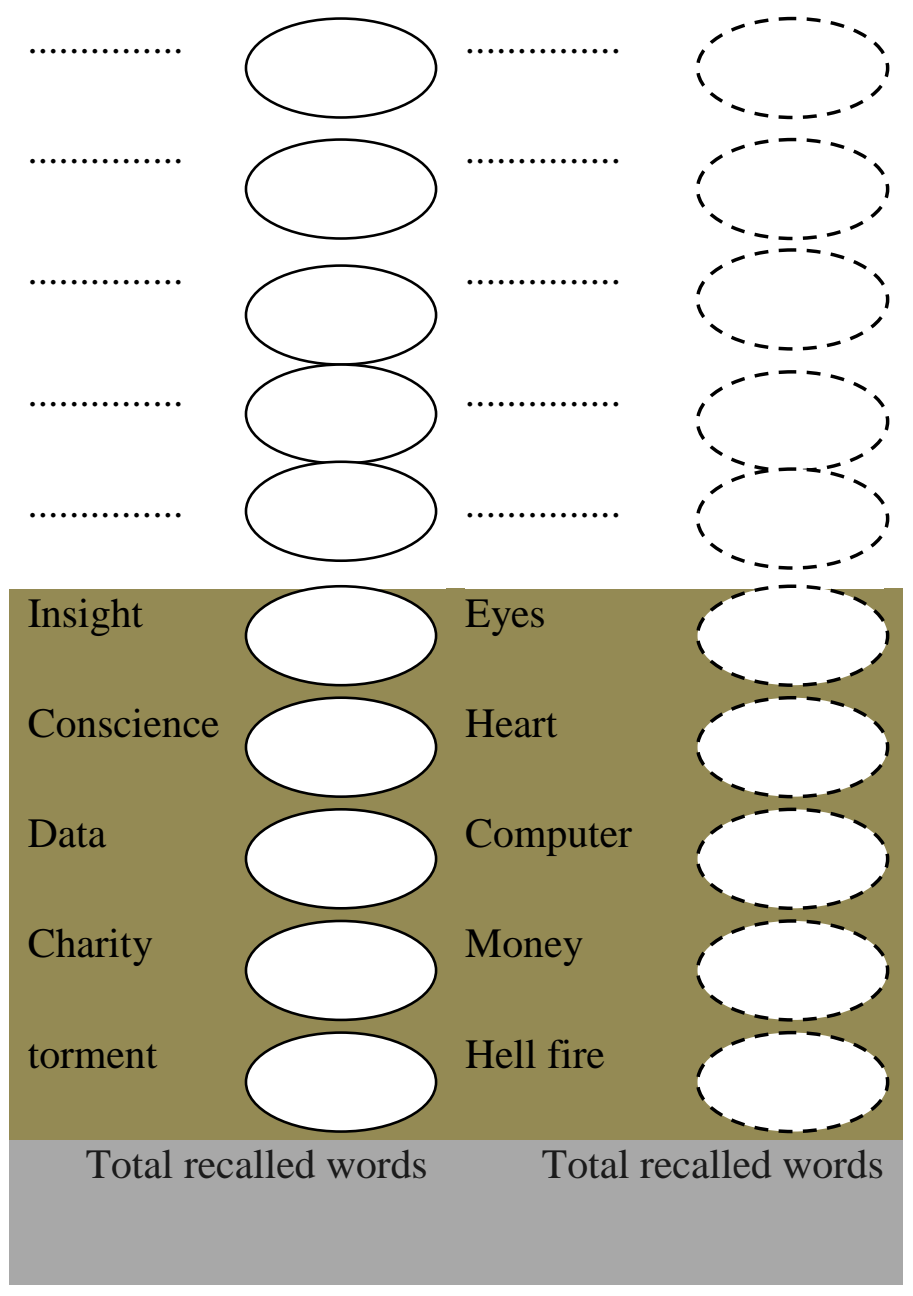

\section{Instructions:}

1. Please mark the words that you can remember in the blanks, and do not write anything inside the oval circles. If you cannot remember the next word, then, write the word next to the word which you can remember. 
2. Please, do not write anything in the third and fourth columns.

\section{Examining the Effect of Motivation on Short-term Memory Recalling of Arabic Abstract and Concrete Words Using Free, Cued, and Serial Recalling Paradigms \\ Participant (1) \\ (Cued recall \\ ) Group(2)}

Note: This form is used to record oral recall

Semantic association
Poem

\section{Instructions:}

1. Please mark $(\sqrt{ })$ the word that the student can remember or mark $(\times)$ to the word, which the student could not remember.

2. Please mark $(\sqrt{ })$ to the assistance aid that you gave to the student. If the student was able to remember the opposite word without any means of help, then do not do anything in the third and fourth columns either if they do not remember the opposite word even using assistance aids. Place the sign $(\times)$ on each. If the student can remember the word using the first assistance aids, place the mark $(\sqrt{ })$ and let the second blank. But if the student 
could not remember the first assistance, place the mark $(\times)$ and on the second $(\sqrt{ })$ if the student was able to remember to use or $(\times)$ if the student could not remember them.

Examining the Effect of Motivation on Short-term Memory Recalling of Arabic Abstract and Concrete Words Using Free, Cued, and Serial Recalling Paradigms Participant (1)

(Cued recall

) $\operatorname{Group}(2)$

Note: This form is usedto recordoralrecall

\begin{tabular}{|c|c|c|}
\hline \multicolumn{2}{|c|}{ Aidstoremember } & List of words \\
\hline Semantic association & First Letter & Concretewords \\
\hline Poem & [Sh] & ration \\
\hline Point toyour eyes & [b] & Eyes \\
\hline $\begin{array}{l}\text { Move your hand as if you } \\
\text { are printing. }\end{array}$ & {$[\mathrm{k}]$} & Data \\
\hline Satan & [j] & Human \\
\hline $\begin{array}{l}\text { Point your hands to your } \\
\text { body. }\end{array}$ & [g] & body \\
\hline $\begin{array}{l}\text { Move your hands as if you } \\
\text { are having your food. }\end{array}$ & [s] & Money \\
\hline $\begin{array}{l}\text { Move your finger } \\
\text { stomimeheartbeat }\end{array}$ & [q] & ce \\
\hline $\begin{array}{l}\text { Imitate and or pretend } \\
\text { suffering feelings }\end{array}$ & [aa] & agony \\
\hline $\begin{array}{l}\text { Point your finger to your } \\
\text { head as if you are } \\
\text { thinking. }\end{array}$ & [d] & Mind \\
\hline Imitatesalternativetorchfire & [n] & \\
\hline
\end{tabular}

\section{Instruction:}

1. Please write the words that you can remember in the blanks, and do not write anything inside the oval circles. If you cannot remember the word, use the helping aids available to you (the first letter or the semantic association), which will be provided by the person who runs the research process.

2. Please, do not write anything in the third and fourth columns unless you are using any of the means of help to remember the word(s) you want. In case you did that, you must 
check $(\sqrt{ })$ in the event of using the first help, and helped you to remember the word, or check $(\times)$ in the event of using the first help and did not help you to remember the word.

3. Follow the same steps to deal with the helping aids in the fourth column (semantic association).

\section{Examining the Effect of Motivation on Short-term Memory Recalling of Arabic} Abstract and Concrete Words Using Free, Cued, and Serial Recalling Paradigms Participant (1)

(Serial recall)

Group (3)

\section{Note:}

This form is used to monitor the oral remembering (Please use here the five non-shaded words only).

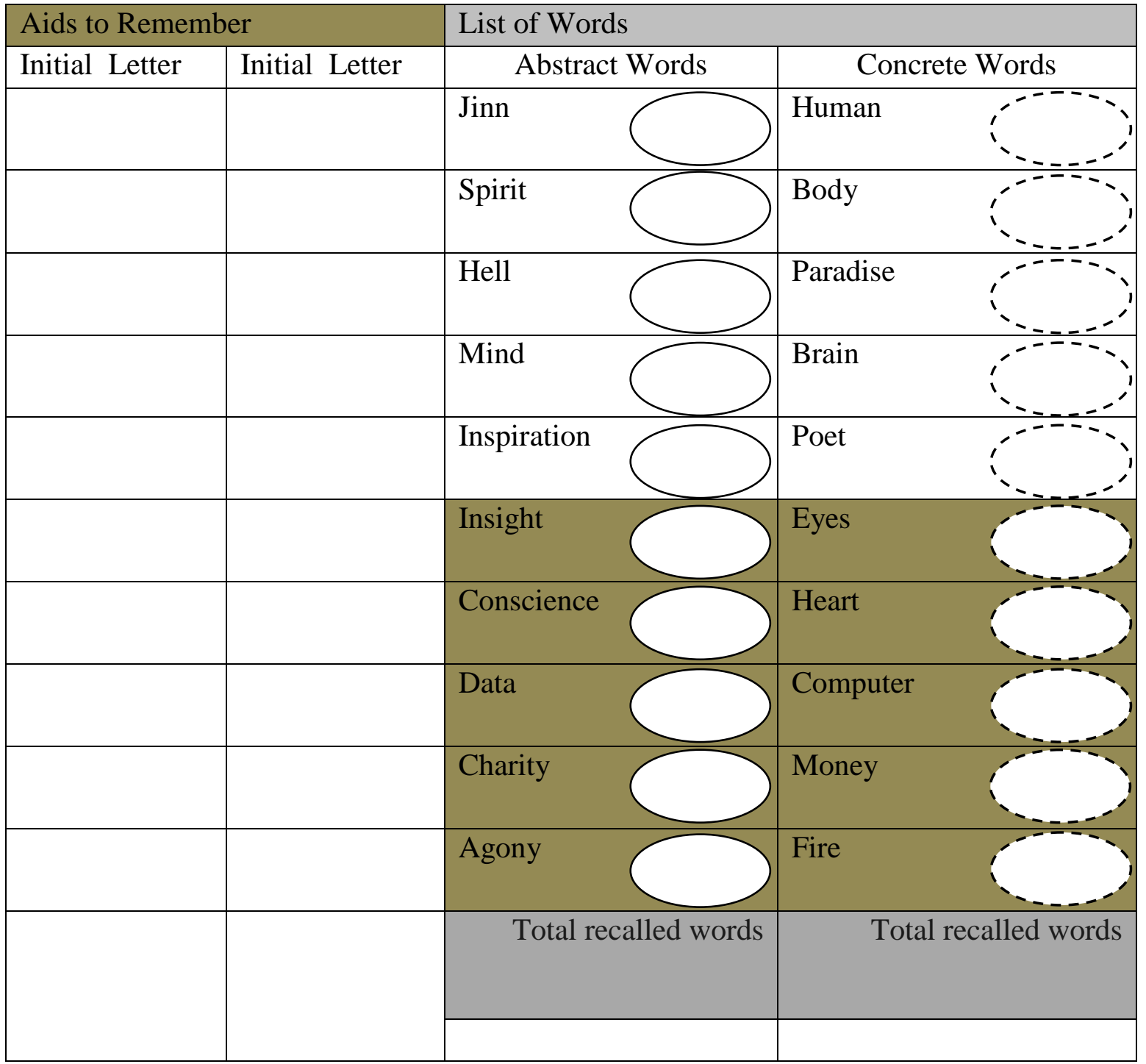

\section{Instructions:}

1- Please write the words in sequence in each of the first and second columns 


\section{Examining the Effect of Motivation on Short-term Memory Recalling of Arabic Abstract and Concrete Words Using Free, Cued, and Serial Recall Paradigms}

2-In case you cannot remember all the words or the next word, just write what you can remember.

3-Do not write anything in the second and third columns

Important note: this table is to be filled out by the researcher. Please do not write anything in this page.

\begin{tabular}{|c|c|c|c|c|c|c|c|}
\hline \multicolumn{8}{|c|}{ Observed effects } \\
\hline 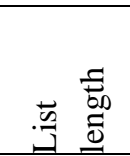 & 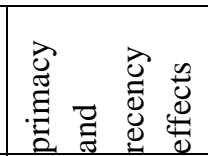 & 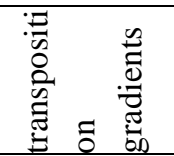 & 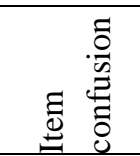 & 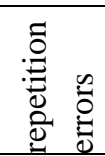 & 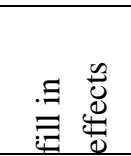 & 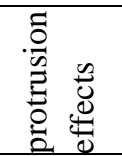 & 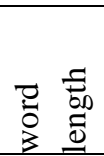 \\
\hline & & & & & & & \\
\hline
\end{tabular}

\section{Instructions for the observed effect:}

1. Do not write anything in the first column;

2. Do not write anything in the second column as well;

3.Suppose that the student remembers every word in the first and second in sequence, then remembers another word instead of the third word - for example the fourth or fifth, please write number (3) on the word uttered by the student;

4.Suppose that the student remembers each the first words in sequence and then remembers another similar word and second instead of the third word - (for example, the word paradise in terms of the similarity in semantic meaning or the word jinn in terms of the similarity in sound, write number (4) on word uttered by the student;

5.Suppose that the student remembers each of the first and second words in sequence and then remembers the second word again instead of the third word or any other word uttered before within the same list, please write number (5) on the word uttered by the student;

6.Suppose that the student remembers each of the first and second words in sequence and then remembers another word instead of the third (for example, the fourth word, but not the fifth or any other word to come), please write number (6) on the word uttered by the student;

7.Suppose that the student remembers each of the first and second words in sequence and then remembers another word which is not in the list of words to be remembered instead of the third word (For example, he remembers a word from the list of abstract words for concrete words or just the opposite), please write number (7) on the word uttered by the student;

8- Do not write anything in the eighth column. 
Examining the Effect of Motivation on Short-term Memory Recalling of Arabic Abstract and Concrete Words Using Free, Cued, and Serial Recall Paradigms

\section{Examining the Effect of Motivation on Short-term Memory Recalling of Arabic Abstract and Concrete Words Using Free, Cued, and Serial Recalling Paradigms}

Participant (1)

(Serial recall)

Group (3)

Note:

This form is used to monitor the recall by writing(Please use here the five non-shaded words only).

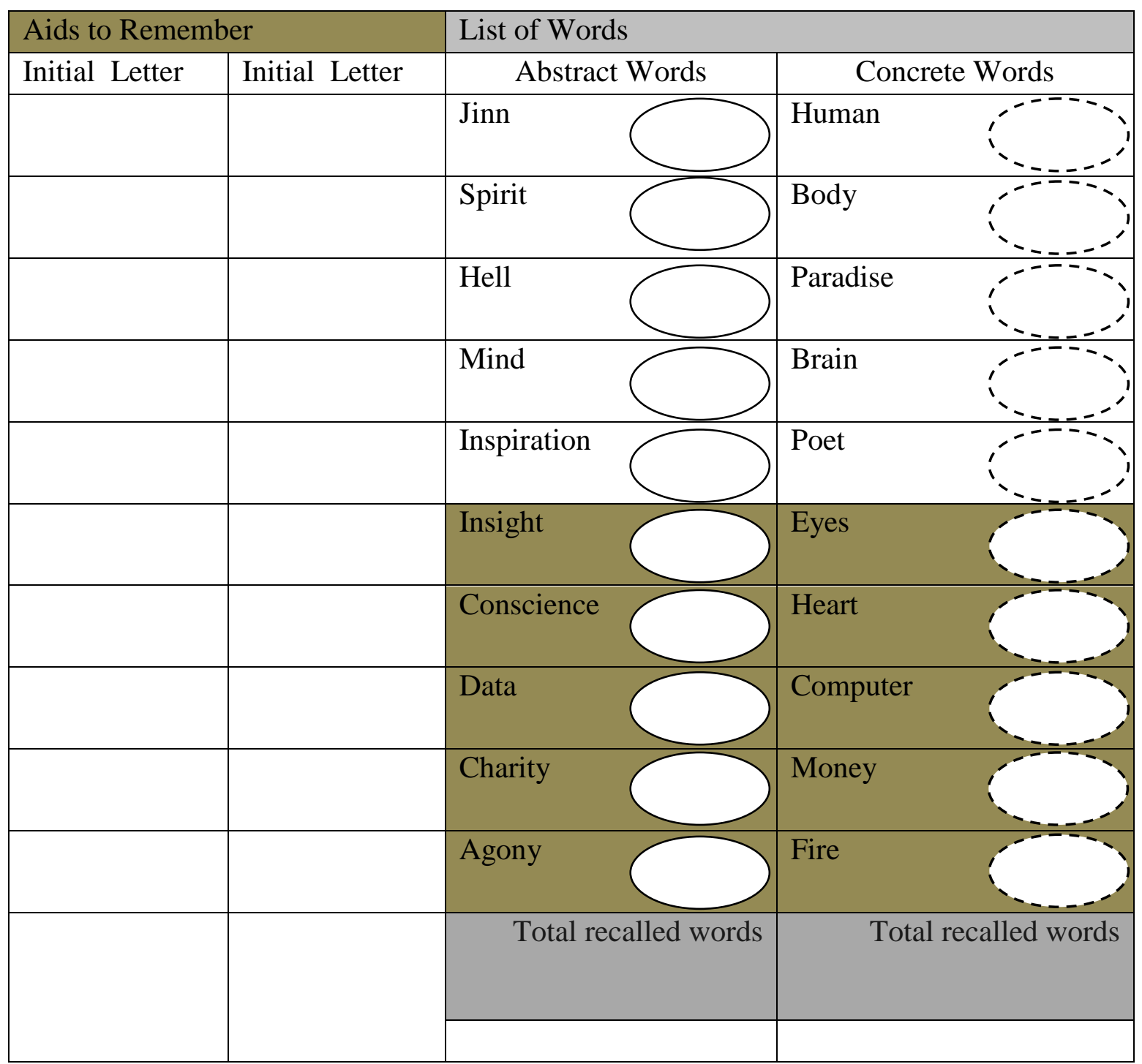

\section{Instructions:}

1- Please write the words in sequence in each of the first and second columns

2-In case you cannot remember all the words or the next word, just write what you can remember. 


\section{Examining the Effect of Motivation on Short-term Memory Recalling of Arabic Abstract and Concrete Words Using Free, Cued, and Serial Recall Paradigms}

3-Do not write anything in the second and third columns

Important note: this table is to be filled out by the researcher. Please do not write anything in this page.

\begin{tabular}{|c|c|c|c|c|c|c|c|}
\hline \multicolumn{8}{|c|}{ Observed effects } \\
\hline 莺 & 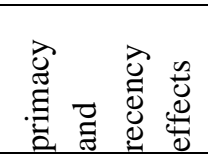 & 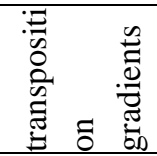 & 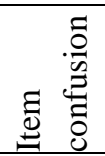 & 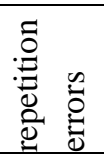 & 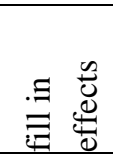 & 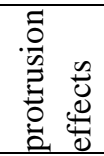 & 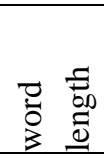 \\
\hline & & & & & & & \\
\hline
\end{tabular}

\section{Instructions for the observed effect:}

1. Do not write anything in the first column;

2. Do not write anything in the second column as well;

3.Suppose that the student remembers every word in the first and second in sequence, then remembers another word instead of the third word - for example the fourth or fifth, please write number (3) on the word uttered by the student;

4.Suppose that the student remembers each the first words in sequence and then remembers another similar word and second instead of the third word - (for example, the word paradise in terms of the similarity in semantic meaning or the word jinn in terms of the similarity in sound, write number (4) on word uttered by the student;

5.Suppose that the student remembers each of the first and second words in sequence and then remembers the second word again instead of the third word or any other word uttered before within the same list, please write number (5) on the word uttered by the student;

6.Suppose that the student remembers each of the first and second words in sequence and then remembers another word instead of the third (for example, the fourth word, but not the fifth or any other word to come), please write number (6) on the word uttered by the student;

7.Suppose that the student remembers each of the first and second words in sequence and then remembers another word which is not in the list of words to be remembered instead of the third word (For example, he remembers a word from the list of abstract words for concrete words or just the opposite), please write number (7) on the word uttered by the student;

8- Do not write anything in the eighth column. 